\title{
Post-flood damage data: requirements for disaster forensic investigation
}

\author{
Martin Dolan ${ }^{1, a}$, Nicholas Walliman ${ }^{2}$, Daniela Molinari ${ }^{3}$, Scira Menoni ${ }^{4}$, Raymond Ogden ${ }^{5}$, Shahrzad Amouzad ${ }^{6}$ and \\ Francesco Ballio $^{7}$ \\ ${ }^{1,2,5,6}$ School of Architecture, Oxford Brookes University, Gipsy Lane, Oxford, UK \\ ${ }^{3,4,7}$ Politecnico di Milano, Department of Civil and Environmental Engineering, Piazza Leonardo da Vinci, 32, Milano, Italy
}

\begin{abstract}
Disaster forensic investigation analyses the unfolding of a disaster and attempts to identify its multiple causes of damage which can lead to (i) improved disaster prevention and management from lessons learnt, and (ii) more effective mitigation measures in the aftermath of a disaster. The way in which damage data are collected after a flood event as well as the types of collected data influences their usability within forensic investigations. In order to explore whether or not existing data can be used for disaster forensic analysis, the European Project IDEA (Improving Damage assessments to Enhance cost-benefit Analyses) is investigating existing gaps in damage information so as to identify possible paths towards improving data quality. This paper focuses in detail on a forensic analysis of the interlinked damage to economic activities and infrastructure in the Severn floods of 2007 in the UK. Besides investigating the usability of existing data, this research investigated: (i) the relative weight of direct and indirect costs to business and infrastructure companies; (ii) to what extent damage to infrastructure has impacted on indirect damage to businesses. Finally recommendations for improving the data for use in forensic investigation are offered.
\end{abstract}

\section{Introduction}

Despite the increased understanding of the science of 'natural' disasters and improved technology, the costs associated with these events are increasing at a rapid rate in both developed countries, where stronger technology and science have failed to stabilise losses, and in developing countries, where the increase in losses are growing much faster than wealth highlighting deficiencies in current research on disasters ${ }^{1}$.

Many approaches to understanding disasters tend to be conducted within the frame of a narrow specialist field such as geological science, meteorology, technology, politics, economics or social sciences. Efforts rarely attempt to delve deeply into the underlying and crossdisciplinary causes with the focus often on reacting to the disaster in order to recover, while the concept of 'building back better' is compromised.

In an attempt to address some of the deficiencies in current disaster research methodologies and improve the long-term recovery and prevention needed to reduce the impacts of such events, forensic investigation has been purposed as an alternative approach that offers a multidisciplinary framework. Forensic investigation aims to identify not only the physical vulnerabilities such as poor building standards and planning policies but also the major policy decisions and smaller incremental social and cultural decisions that lead to accumulated vulnerabilities. ${ }^{1}$

Another trait of forensic investigation is that the research must be carried out independently and free from influence from any external bodies while still maintaining the authority and support of all public and private bodies involved and affected. This allows the investigation to achieve unadulterated results and report on the multitude of actions and responsibilities which account for the damage caused ${ }^{2}$. The aim of this type of investigation is not to pin blame on any one stakeholder but to expose the myriad of contributing factors and aid in the identification of the most effective responses in order to avoid a reoccurrence of the damage caused.

One of the principles of forensic investigations is the ability to be able to accumulate evidence of good practices by examining the different impact of similar events in different locations or the effects of a single event on different sectors in the same geographical location.

The participation of experts in a wide range of professional disciplines from natural sciences, social and economic studies, engineering, public health, emergency planners and humanitarian relief organisations is essential for an in-depth forensic investigation and input from as

a Corresponding author: Martin Dolan: mdolan@brookes.ac.uk 
many stakeholders as possible will lead to improved understanding of the causes and effects of damage and suitable mitigation measures to be implemented.

However, a critical challenge in forensic investigation is the way in which data are collected, analysed and shared among these stakeholders and how this data is also relayed to the forensic investigating team. A lack of data or inaccessibility can restrict the essential multidisciplinary insight that defines the approach. Where certain principle stakeholders are unwilling or unable to cooperate in the investigation the completeness of the results can be compromised.

Reliability and completeness of data is crucial in being able to ascertain the reality of what occurred on the ground. When dealing with data that is collected during and in the aftermath of an event of high uncertainty, such as a natural disaster, this can often be difficult task to achieve.

To explore whether or not existing data can be used for disaster forensic analyses, several case studies were analysed within the European Project IDEA (Improving Damage assessments to Enhance cost-benefit Analyses). The main objective was to investigate existing gaps in damage information so as to identify possible paths toward improvement of both data quality and procedures to collect and manage them.

Assessing the reliability of damage data collection, storage and management for forensic investigations requires a deep understanding of the present state of art, as well as of limits to be overcome and useful requirements to be supplied by tools developed by the IDEA project.

This paper focuses in detail on the Severn flood in the UK in 2007. Following the severe flooding in Gloucestershire and elsewhere in 2007, the UK government commissioned Sir Michael Pitt to examine the response and to provide lessons to be learned from that event. The Pitt Review 2007 made 92 recommendations to the government including advice on improving data collection and recording. The report noted that effective information flows during the response and recovery periods are necessary.

The focus of this case study is on identifying the vulnerabilities that lead to damage to commercial and industrial activities. In detail, observed direct and indirect damages are analysed according to a forensic approach. Particular care is taken to analyse indirect damage due to direct damage, as well as damage to infrastructure, as it is often the case that business activities suffer because of disruption of essential services. It is through this process that the research aimed to understand the requirements for damage data in order to carry out a successful forensic analysis.

Besides investigating the usability of existing data, this process allowed the exploration of:

(i) what is the relative weight of direct and indirect costs to business and infrastructure companies;

(ii) to what extent damage to infrastructure has impacted on indirect damage to businesses.
The methodological approach to the study is presented here before findings and results, with their implications for forensic analysis and data, are discussed. Finally a selected number of recovery interventions for the business sector and utilities were analysed to assess to what extent the forensic investigation has been used or may be used to guarantee effective investments.

\section{Methodology}

The methodological approach entailed firstly the collection and analysis of existing data obtained from reports, databases and directly from stakeholders.

This was followed by carrying out a forensic analysis of the Severn floods of 2007 which was considered a suitable case study due to the extensive coverage and post-disaster analysis carried out at all levels.

Finally the results from the forensic analysis were assessed for their accuracy and applicability which led to a judgement of the quality of the data used to carry out the forensic analysis.

\subsection{Data collection and analysis}

\subsubsection{Stakeholder identification and categorisation}

A review of event reports and literature allowed first to identify principle stakeholders. A questionnaire was then sent to individual stakeholders so that profiles were created for each stakeholder, based on questionnaires results. Preliminary information was further integrated with knowledge acquired by direct interviews arranged with engaged stakeholders. Interestingly, further stakeholders were identified through such discussions.

This was followed by engagement with stakeholders and the categorisation of these into data owners, users or collectors. Stakeholders were also categorised as public or private organisations, with public groups relating to policy level government bodies, county councils, district councils and emergency services. Private stakeholders included insurance companies, service providers such as water companies, electricity providers, gas and telecommunications companies, private businesses and voluntary organisations.

As regard data owners, characterisation implied the identification of (i) which data they are responsible for, (ii) at which spatial and temporal scales, (iii) with what rights (e.g. private or public owners, voluntarily or by law, etc.) and (iv) tools used for the storage of data. With respect to data collectors, investigation concerned (i) reasons for data collection, (ii) type of collected data and spatial and temporal scales of interest (iii) tools and procedures presently implemented, and (iv) available human and economic resources. Data users were characterised in terms of (i) data of interest, (ii) scales of interest and (iii) uses of data.

Moreover links among the different stakeholders were identified as some data are collected or owned by certain stakeholders who shared them with other stakeholders for the different purposes related to risk management. 
Finally, stakeholders that are/could be in charge of coordinating the data analysis and representation were defined. Previous experience has shown that without such entity taking care of integrating the data no comprehensive picture of disaster impacts will be ever possible

\subsubsection{Data gathering}

The first step of data gathering was the identification of data sources (i.e. owners), starting from information obtained during meetings/interviews with stakeholders. Then data were then physically collected, collated and stored. According to the data source, data collection involved field surveys, collection of documents in paper form or digital data (from both public and private sources) and acquisition of open data.

\subsubsection{Data analysis}

An assessment of the comprehensiveness of the collected data was performed. In detail, availability of data to depict the full range of likely impacts as well as their drivers (i.e. hazard, exposure and vulnerability factors) was assessed. Finally, a categorisation of main data sources was carried out based on format and level of detail in order to make the use of this data more suitable for the scale of forensic analysis desired.

\subsection{Forensic analysis}

In the process of forensic analysis it is important to understand the ultimate goal of carrying out such investigations. In the case of disaster vulnerability analysis we may, for example, aim to assess the impact of varying different factors on different sectors of the exposed community. In order to be able to carry out a variety of analyses, it is essential to quantify as many values and variants as possible.

In this particular case, it was extremely valuable to gain insight into how particular sectors were affected in different ways by varying vulnerability factors in order to establish the most beneficial actions to take in building resilience. This section explains how to arrive at the point where this is possible.

The forensic analysis began with the creation of a timeline of events as they unfolded, beginning with the first evidence of heavy rainfall. The entire event unfolded over quite a long period and emergency operations and other actions took place outside of the research area and also unrelated to infrastructure and business. These events were considered to be outside the limits of this study.

It was deemed necessary to treat each individual element and sector of the infrastructure network separately by carrying out individual forensic investigations for each in order to firstly establish the direct impact, and then take an overarching approach to how direct impact to each of these sectors indirectly impacted on businesses. This decision was taken due to the complexity of the infrastructure network and the interrelations within the system.

From the timeline an extensive list of the perceived contributing factors was created. This included such aspects as the suitability of emergency response plans in place before the flood and the times of flood warnings. Following this, the factors were categorised depending on whether they were considered to be related to the hazard or to physical, social, organisational or systemic vulnerability. Some factors fell into several of these categories simultaneously and the categorisation reflected this. This process is illustrated in Table 1 below.

Following this a judgement was made as to whether these factors contributed to or reduced damage or both. This is relevant in that some factors were a combination of both. For example, the shutting down of a water treatment plant protected the machinery of the plant and thus the water company's assets and reduced long term damage but it had an impact on businesses and residences in the short term.

This exercise built up a strong picture of where the largest vulnerabilities lay. For example, the majority of contributing factors may lie in the organisational vulnerability of a company or agency. This is to say that emergency planning, management and decision making would be the primary contributing factors in causing damage. Additionally systemic issues may be prevalent in the causing of damage as the failure of a single element of an infrastructure system can result in large-scale impact.

Following this step, an estimated weight was assigned to the direct impact of each factor on the main affected sector. In order to do this, firstly a judgement was made on which sectors were affected. For example, this could include businesses, residences, infrastructure companies, emergency operations, government agencies etc. Once the affected sectors are decided on, a decision is made on which sector was affected by each factor. This is done by entering an ' $\mathrm{X}$ ' under the affected sector as shown in Table 2 below. In this case it is clear that the hazard affected all sectors while the large amount of information to deal with affects mostly emergency services and the Environment Agency.

The next step in the process was to make a judgement of the weight of the impact on each sector for each factor. This is done on a scale of 1-3 with 1 being minimal, 2 being significant and 3 being major.

A value of $-1,-2$ or -3 may be assigned to factors if it is believed that these factors contributed more to a reduction of vulnerability than to an increase. The importance of a negative value is revealed in the following step when values are accumulated and thus reflect on the overall weight of contributing factors whether they reduce or contribute to damage. The value of this is clear where one particular factor may both 


\begin{tabular}{|c|c|c|c|c|c|c|c|c|}
\hline \multirow[b]{2}{*}{ factor } & \multicolumn{6}{|c|}{ type of factor } & \multirow[b]{2}{*}{$\begin{array}{c}\text { reduction } \\
\text { of } \square\end{array}$} & \multirow[b]{2}{*}{$\begin{array}{l}\text { increasin } \\
\mathrm{g} \text { of }\end{array}$} \\
\hline & haza ${ }^{\mathbf{T}}$ & $\begin{array}{l}\text { physical } \\
\text { vulnera }\end{array}$ & $\begin{array}{c}\text { social } \\
\text { vulnera }\end{array}$ & $\begin{array}{c}\text { organisati } \\
\text { onal }\end{array}$ & $\begin{array}{l}\text { Economir: } \\
\text { Vulneral }\end{array}$ & $\begin{array}{l}\text { systemic: } \\
\text { yulneri }\end{array}$ & & \\
\hline Flood warnings & & & & $x$ & & & & $x$ \\
\hline $\begin{array}{l}\text { Many customer dependent on a single } \\
\text { water main }\end{array}$ & & & & & & $x$ & & $x$ \\
\hline Plant shut down as precautionary measure & & & & $x$ & & $x$ & & $x$ \\
\hline $\begin{array}{l}\text { Limited flexibility in system to draw water } \\
\text { from other sources in event of failure }\end{array}$ & & & & & & $x$ & & $x$ \\
\hline Misuse of bow sers resulting in loss of water & & $x$ & $x$ & $x$ & & & & $x$ \\
\hline Road diversions & & $x$ & & $x$ & & & & $x$ \\
\hline $\begin{array}{l}\text { Located on banks of River Severn near } \\
\text { confluence with Avon }\end{array}$ & & $x$ & & & & & & $x$ \\
\hline $\begin{array}{l}\text { Increase in w ater usage following news of } \\
\text { imminent flooding }\end{array}$ & & & $x$ & & & $x$ & & $x$ \\
\hline
\end{tabular}

Table 1 Forensic analysis listing contributing factors assigned to vulnerability class

\begin{tabular}{|c|c|c|c|c|c|c|c|}
\hline \multirow[b]{2}{*}{ factor } & \multicolumn{4}{|c|}{ affected sector } & \multirow[b]{2}{*}{ Coun -} & \multirow[b]{2}{*}{$E^{-}$} & \multirow[b]{2}{*}{$\mathbf{n}$} \\
\hline & residence: ${ }^{\nabla}$ & business $\bar{T}$ & infrastructure: $\nabla$ & $\begin{array}{c}\text { emergency } \\
\text { services }\end{array}$ & & & \\
\hline Flood w arnings & $x$ & $x$ & & $x$ & & $x$ & \\
\hline $\begin{array}{l}\text { Many customer dependent on a single } \\
\text { water main }\end{array}$ & $x$ & $x$ & & & & & \\
\hline Plant shut down as precautionary measure & $x$ & $x$ & & & & & \\
\hline $\begin{array}{l}\text { Limited flexibility in system to draw water } \\
\text { from other sources in event of failure }\end{array}$ & $x$ & $x$ & & & & & \\
\hline Misuse of bow sers resulting in loss of water & $x$ & $x$ & & & & & \\
\hline Road diversions & $x$ & $x$ & $x$ & & & & \\
\hline $\begin{array}{l}\text { Located on banks of River Severn near } \\
\text { confluence with Avon }\end{array}$ & $x$ & $x$ & & & & & \\
\hline $\begin{array}{l}\text { Increase in w ater usage following news of } \\
\text { imminent flooding }\end{array}$ & $x$ & $x$ & & & & & \\
\hline
\end{tabular}

Table 2 Assigning of impact to affected sectors 


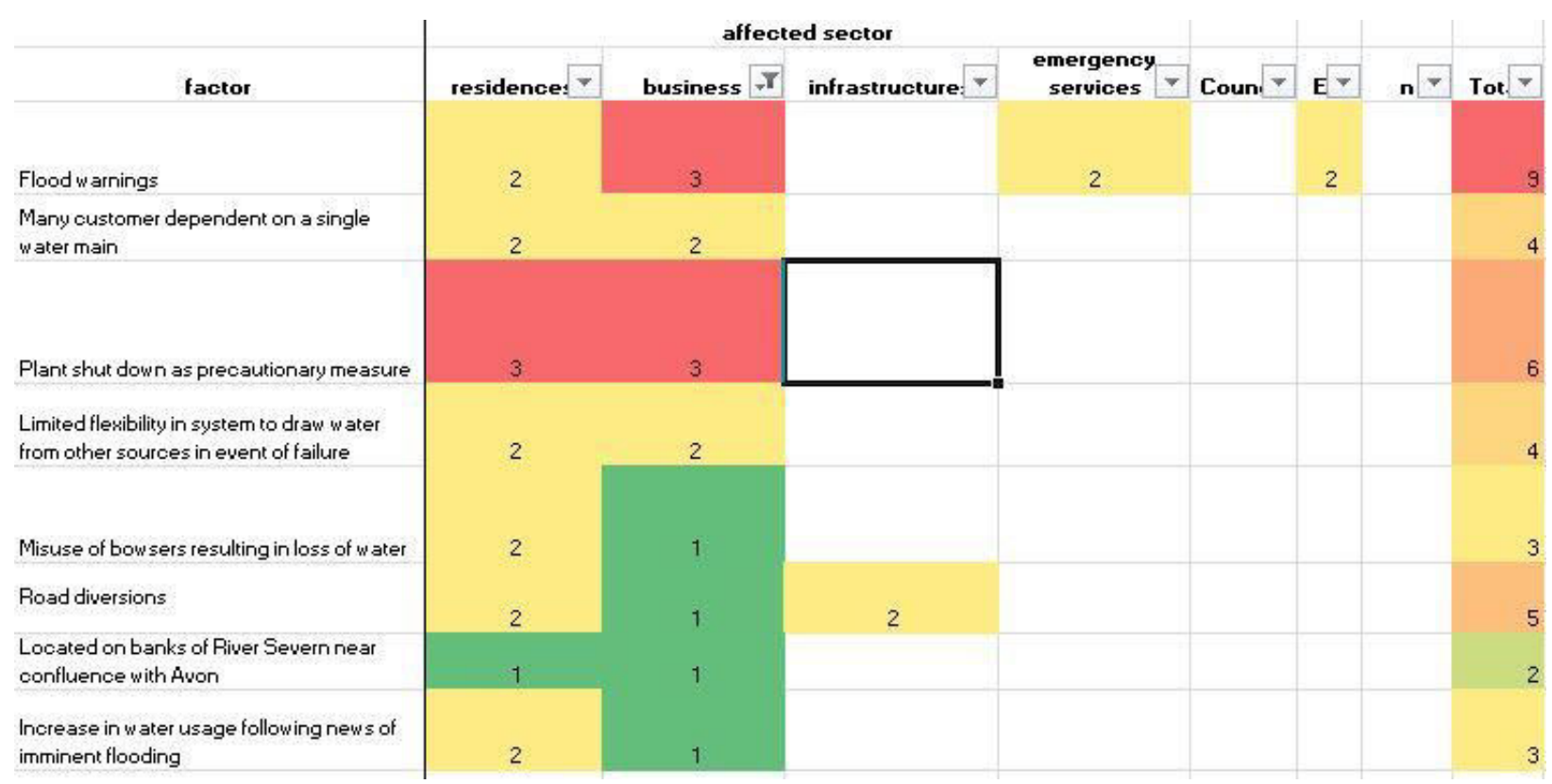

Table 3 Assigning of weight to impact on affected sectors. Total is calculated by summing weights across all sectors.

\begin{tabular}{|c|c|c|c|c|c|c|c|c|}
\hline \multirow[b]{2}{*}{ factor } & \multicolumn{6}{|c|}{ type of factor } & \multirow[b]{2}{*}{ reduction } & \multirow[b]{2}{*}{$\begin{array}{l}\text { increasin } \\
g \text { of } *\end{array}$} \\
\hline & haza ${ }^{\top}$ & $\begin{array}{l}\text { physical } \\
\text { vulnera }\end{array}$ & ${ }_{\text {vulnera }}^{\text {social }}$ & $\begin{array}{l}\text { organisari } \\
\text { onal }=\end{array}$ & $\begin{array}{l}\text { Economir: } \\
\text { Vulneral }\end{array}$ & $\begin{array}{l}\text { systemir: } \\
\text { vulnera }\end{array}$ & & \\
\hline Flood warnings & & & & 4 & & & & 4 \\
\hline $\begin{array}{l}\text { Many customer dependent on a single } \\
\text { water main }\end{array}$ & & & & & & 4 & & 4 \\
\hline Plant shut down as precautionary measure & & & & 6 & & 6 & & 6 \\
\hline $\begin{array}{l}\text { Limited flesibility in system to draw water } \\
\text { from other sources in event of failure }\end{array}$ & & & & & & 4 & & 4 \\
\hline Misuse of bow sers resulting in loss of water & & 3 & 3 & 3 & & & & 3 \\
\hline Road diversions & & 5 & & 5 & & & & 5 \\
\hline $\begin{array}{l}\text { Located on banks of River Severn near } \\
\text { confluence with Avon }\end{array}$ & & 2 & & & & & & 2 \\
\hline $\begin{array}{l}\text { Increase in water usage following news of } \\
\text { imminent flooding }\end{array}$ & & & 3 & & & 3 & & 3 \\
\hline
\end{tabular}

Table 4 Total weight of factor is substituted back into vulnerabilities columns in order to calculate total significance for each vulnerability. 
FLOODrisk 2016 - $3^{\text {rd }}$ European Conference on Flood Risk Management

\begin{tabular}{|c|c|c|c|c|c|c|}
\hline factor & hazarc ${ }^{\top}$ & $\begin{array}{c}\text { physical } \\
\text { vulnerabili }\end{array}$ & $\begin{array}{c}\text { social } \\
\text { vulnerabili } \mathbf{}\end{array}$ & $\begin{array}{l}\text { organisational } \\
\text { vulnerabilit }\end{array}$ & $\begin{array}{c}\text { Economic } \\
\text { Vulnerabilit }\end{array}$ & $\begin{array}{c}\text { systemic } \\
\text { vulnerabil }\end{array}$ \\
\hline Plant shut down as precautionary measure & & & & -3 & & -3 \\
\hline Obliged to supply 10 litres of water per person & & & -4 & -4 & & -4 \\
\hline Hub and Spoke approach to bowsrer refill & & & & -2 & & \\
\hline Built on artificially raised ground & & -2 & & & & \\
\hline $\begin{array}{l}\text { Reorganisation of command structure. STW } \\
\text { Gold Team established under control of }\end{array}$ & & & & -2 & & \\
\hline Site evacuated & & & & -1 & & \\
\hline $\begin{array}{l}\text { Installation of semi-permanent flood } \\
\text { protection after the plant had already been } \\
\text { flooded }\end{array}$ & & 0 & & 0 & & \\
\hline Total Reduction & 0 & -2 & -9 & -28 & & -18 \\
\hline Total Increase & 0 & 11 & 1 & 11 & & 9 \\
\hline Overall & 0 & 9 & -8 & -17 & & -9 \\
\hline
\end{tabular}

Table 5 Total weight of each vulnerability calculated by summing accumulated impact. 
reduce and contribute to damage for varying sectors. This is shown in Table 3 .

In order to be able to analyse the real weight of factors of vulnerability and be able to comment on the varying degrees of relevance for different sectors it was essential to be able to apply values to the importance of each factor. In order to do this, informed judgements were made and there was an element of subjectivity. Statistically speaking, by combining the sums of various subjective values, any discrepancies are aggregated and cancel each other out. A cumulative approach is thus beneficial. So the next step is a return to the previous section where the above weighted values are added together and input into the vulnerabilities columns as shown in Table 4. This gives a cumulative number of the impact of each vulnerability factor based on comparable parameters. ${ }^{3}$ This then allowed for the calculation of the total impact of each vulnerability in order to establish which is the most critical as shown in Table 5 .

Having carried out this exercise for each individual element or sector of the infrastructure network, the factors that were judged to have had an indirect impact on businesses were then translated into the forensic analysis of the business sector and the same process then carried out again. This narrows the field of analysis and allows for the assessment of importance of factors based on their perceived impact. Similar analysis can then be carried out offering insight into the categories of vulnerabilities.

\section{Infrastructure and business}

As part of the IDEA project this paper focuses specifically on the indirect impact of infrastructure failure on businesses in the 2007 Severn Trent floods in the U.K..

In a report produced as part of the FloodProBE project, ${ }^{4}$ critical infrastructure is defined as that infrastructure which is essential for the functioning of society, whose failure would seriously affect many people. The report offers an assessment of the vulnerability to infrastructure which includes an analysis of the effects of element failure on a network. The approach adopted accounts for the secondary 'knock-on' effects of infrastructure failure and the inter-dependency of infrastructures. In fact the study focuses more on these secondary impacts than on the direct impacts and offers a relevant analysis of the vulnerability of infrastructure and its impact on businesses.

Rapid recovery of businesses may be hampered more by the loss of critical infrastructure than by direct physical damage. Tierney ${ }^{5}$ found businesses were forced to close by disruption to utility services more often than by direct damage during 1993 flooding in the U.S. Midwest. $15 \%$ of Des Moines businesses experienced flood damage while $42 \%$ were forced to close due to lack of regular services such as electricity or water. If a business itself is not directly impacted by a disaster, damage to offsite lifelines will still have a negative impact on recovery.

In a regional context, the most important elements are electricity, water supply, wastewater drainage systems, transportation, and communication systems. Welfare and social systems such as food distribution centres and financial centres as well as emergency services are also of importance for the functioning of normal services during a flood event ${ }^{6}$. In order to quantify the impacts on society it is important to assess the duration of disruption, the area affected, the number of people affected and combinations of these, having first analysed the effect of element failure on the network and then the effect of this on other networks.

Similar problems are faced by businesses subjected to disruption of the road transport system due to the damage to primary roads which may be closed for some time.

Organisations, businesses and infrastructure systems can be considered as networks consisting of various actors and information flow. Studies of networks demonstrate that networks consisting of a few key nodes, or hubs, and high connectivity between them, followed by an increasing number of other nodes with decreasing connectivity are less vulnerable to failure due to a deletion of nodes or breaking of links ${ }^{7}$. Because external shocks to the network can happen at random the likelihood that a peripheral hub would be affected is small and the network will not lose its connectedness. However, many networks can have a weakness in that they are vulnerable to a shock that affects the most highly connected hubs. The Internet is one example of this in that internet traffic is rarely disrupted by disruptions to smaller servers but can be extremely disrupted by a failure of a few key hubs ${ }^{8}$. Such perspectives suggest that the more reliant a business is on the satisfactory operation of infrastructure, the more vulnerable it will be to the impacts of climate related incidents such as flooding. Table 6 below shows a diagramatic example of how infrastructures relate to each other and how other sectors rely on the functioning of the system.

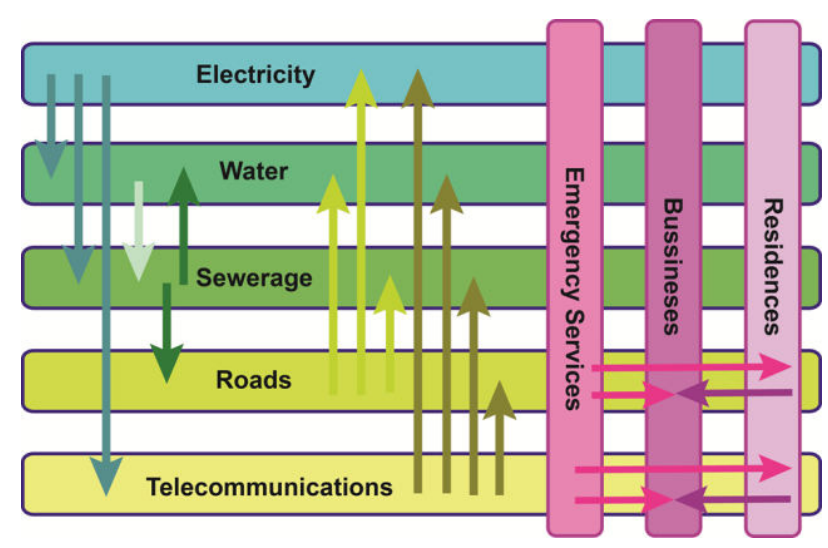

Table 6 Interdependancies within infrastructure system and with other sectors.

\section{The Severn Trent Floods}

This particular case study focuses on the Gloucestershire area of the U.K. which has experienced severe flooding in recent years, most notably in 2007 which resulted in the largest emergency operation in the U.K since World War II. In June and July 2007 more than 55,000 properties were flooded, 7,000 people had to 
be rescued and 13 people died. Nearly 500,000 people were left without water or electricity and the insurance bill was expected to be more than $£ 3$ billion.

\subsection{Infrastructure}

During the flooding of 2007, infrastructure in the Gloucestershire area was heavily impacted with the closure of the Mythe Water Treatment plant leaving 350,000 people without drinking water for up to 16 days, an estimated 10,000 people stranded on the M5 motorway and 42,000 people left without power when a controlled shutdown of the Castlemeads Power Station was carried out being just a handful of examples of widespread damages to infrastructure. As previously outlined in Section 3, direct impacts to infrastructure can lead to indirect impacts to business and this forensic analysis aimed to identify and quantify these impacts and their root causes.

In a regional context as is the case in Gloucestershire, the most important elements are electricity, water supply, wastewater drainage systems, transportation, and communication systems. Welfare and social systems such as food distribution centres and financial centres as well as emergency services are also of importance for the functioning of normal services during a flood event.

Due to the complex interdependencies of infrastructure networks, with many elements relying on the operation of one or many others, it is difficult to equate the impact the failure of one element has on a region or the businesses in that region.

For this reason it was important to carry out forensic investigations for each sector of infrastructure in order to establish any indirect impacts that occurred between different infrastructures.

\subsubsection{Water}

Water treatment plants represent a critical infrastructure in their provisions of healthy drinking water to a large number of people across the country. In the case of the flooding in Gloucestershire, this is the service that was most disrupted and which consequently had the biggest impact on the businesses and public as a whole. As a particularly clear and poignant example, the failure of the Mythe water treatment plant owned by Severn Trent Water (STW), resulted in loss of drinkable water to over 350,000 people for up to 16 days. This extreme incident was coupled with widespread minor incidents and damage to other assets such as the sewerage system and other smaller pumps. Severn Trent Water estimate the total cost to the company due to direct damage to be in the region of $£ 25$ million and $£ 35$ million.

Forensic analysis of the damage to STW's infrastructure was carried out as outlined in Section 2.2 and the following results emerged.

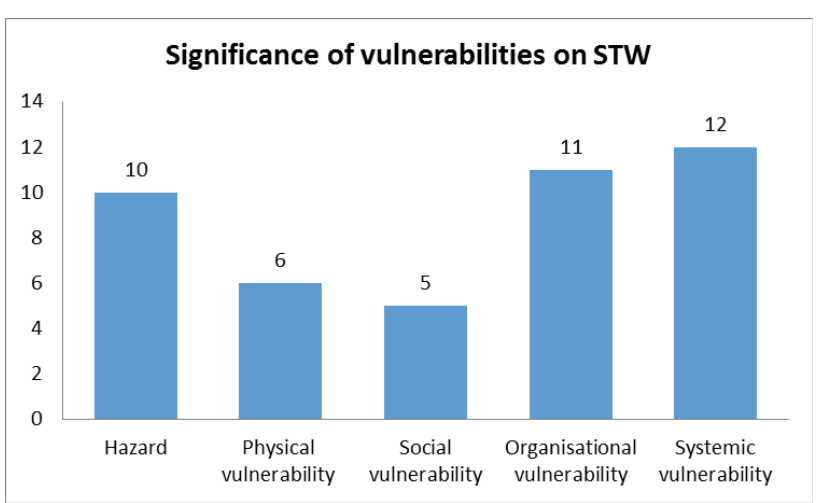

Figure 1

The most significant vulnerability that resulted in damage was systemic vulnerability due to the fact that many people in the area were reliant on a single source of drinking water. In addition to this, the treatment plant was unable to draw on other source of water and reservoirs.

Systemic vulnerability was followed by organisational vulnerability in terms of significance. The range of organisational factors was not confined to just those of the plant management but also to decisions made about emergency management and flood defences. One of the most significant factors was the inadequacy of the emergency plan for the plant that was in place prior to the flood in dealing with the scale and extent of the flooding. Physical and social vulnerabilities are the least significant of the identified vulnerabilities. The physical vulnerability in this case was minimal mainly due to some decisions such as the one to shut down the water treatment plant helped to reduce the overall impact of the flooding. Social vulnerabilities were less significant due to the isolated and technical nature of infrastructure. In this case social aspects became involved mostly in the emergency operation and provision of water to customers. Although significant in their own right, they contribute less to damage than the others

Following these vulnerabilities was the hazard itself. Without the flood there would be no flood damage. In this sense, the hazard, although amplified by certain factors, is unavoidable from the perspective of the water company.

In terms of the most significant individual factors, the list below illustrates the contributing weight of each. It is worth noting that the weighted factor considers both contributing and reducing factors. For this reason the shutting down of the plant, although it affected many people in the short term, reduced the long term damage that would have resulted if essential equipment was damaged. 


\begin{tabular}{|l|l|}
\hline Row Labels & Sum of Total \\
\hline flood defence systems & 3 \\
\hline Located on banks of River Severn near & 3 \\
confluence with Avon & \\
\hline Many customer dependent on a single water & 3 \\
main & 3 \\
\hline Rainfall & 3 \\
\hline Water levels in River Severn & 2 \\
\hline EA Peak water level predictions & 2 \\
\hline Flood warnings & \\
\hline Increase in water usage following news of & 2 \\
\hline imminent flooding & \\
\hline Limited flexibility in system to draw water from & 2 \\
\hline other sources in event of failure & 2 \\
\hline Mythe WTW Flood Emergency Response Plan & 2 \\
\hline Obliged to supply 10 litres of water per person & 2 \\
\hline Road diversions & 2 \\
\hline Speed of rise in river levels & 2 \\
\hline Unprecedented scale and level of flooding & 1 \\
\hline Contingency plans in case of system failure & 1 \\
\hline Hub and Spoke approach to bowsrer refill & 1 \\
\hline Misuse of bowsers resulting in loss of water & 1 \\
\hline Participation with Gold Command team & 0 \\
\hline Plant shut down as precautionary measure
\end{tabular}

Table 7 List of most significant contributing factors affecting Severn Trent Water

The sectors that were most affected indirectly by the damages to the water infrastructure were residences, businesses, other infrastructure, emergency services and government agencies such as the EA and district councils. The graph below illustrates the weight of the impacts on each sector with residents and businesses being the most impacted.

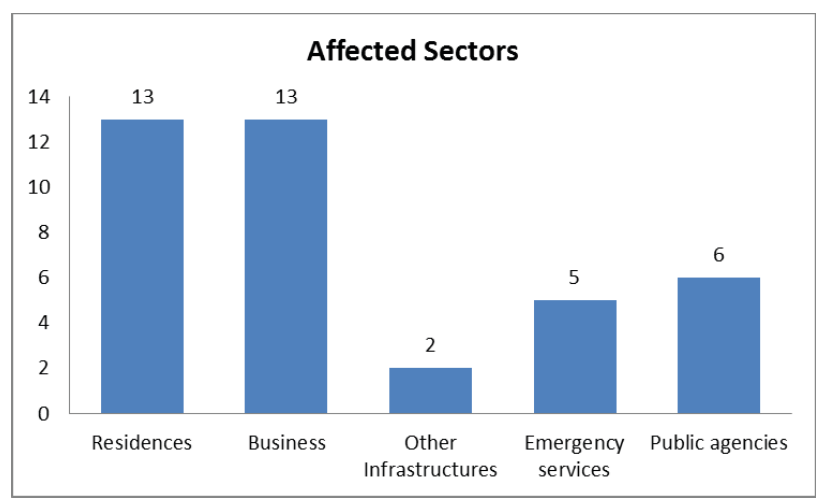

Figure 2

\subsubsection{Roads and Transport}

As a result of the flooding the roads and transport network was seriously disrupted. Motorists and public transport users found themselves stranded as the transport network struggled to cope with the conditions - an estimated 10,000 motorists were stranded overnight on the M5 between junctions 10 and 12 and on some other roads, and approximately 500 people were stranded at Gloucester Railway Station as the railway network failed. Rest centres were established in Moreton-in-Marsh,
Chipping Campden, Gloucester, Cheltenham, and Tewkesbury to help people that could not get home. These rest centres collectively accommodated around 2000 people at the height of the emergency. ${ }^{9}$

The forensic analysis of the network revealed the following results.

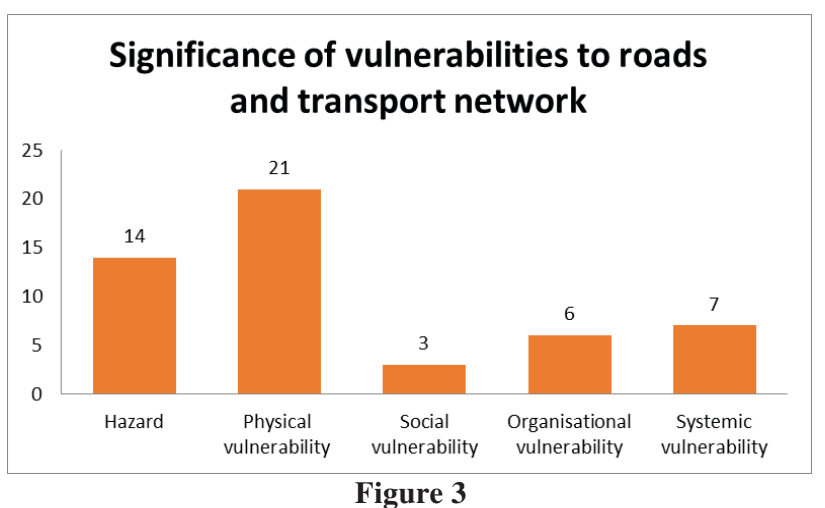

As can be seen, the most significant vulnerability is the physical characteristic of the system. This relates mostly to the deterioration of assets on the network, physical damage to roads, a lack of maintenance, restricted access caused by water on the roads, congestion and the resulting difficulties for emergency operations that resulted from congestion.

As was the case in the water network, the hazard is again significant but since it is out of the control of the infrastructure sector and therefore must be considered separately to the other vulnerabilities.

Systemic vulnerabilities were the next most significant aspect for the transport network with restrictions in the network that lead to congestion. It was noted that improved use of secondary roads and dual-lane motorways would have led to fewer disruptions. The rail network by its nature is quite susceptible to systemic vulnerabilities and was affected greatly.

Organisational vulnerability is the next most significant vulnerability and relates to decisions taken within the sector that lead to disruptions such as the inefficiency in the communication of information to motorists, cooperation with local authorities and emergency services which were hindered by a lack of understanding due to communication issues and inefficiencies in emergency plans in dealing with an event of such a scale. However, actions to provide support for those stranded on roads and railways were overall quite effective.

Social vulnerabilities stemming from motorists' lack of knowledge about how to react in such events were less significant but nonetheless did exist.

In terms of the most significant individual factors, the list below illustrates the contributing weight of each. It is worth noting that the weighted factor considers both contributing and reducing factors. For this reason, while access to emergency supplies for example, was restricted, 
the network in general operated well and resulted in very few threats to life. The biggest impact was to the normal operation of businesses and daily life.

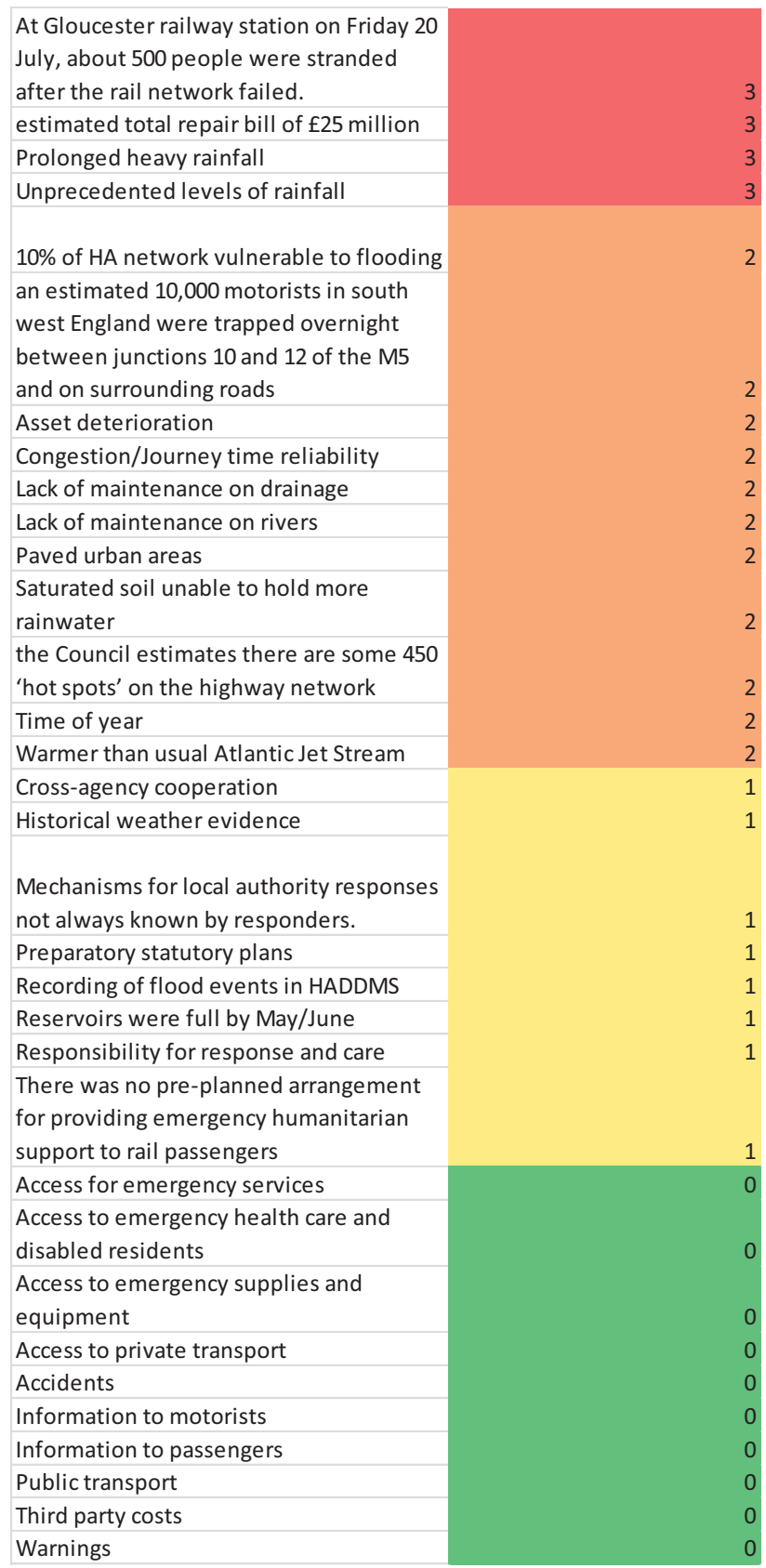

Table 8 List of contributing factors affecting roads and transport network

As shown in Figure 4 the sectors most affected by direct damage to the transport network were residents/motorists and emergency services, followed by businesses and public agencies. This is in contrast with the water network which affected businesses most.

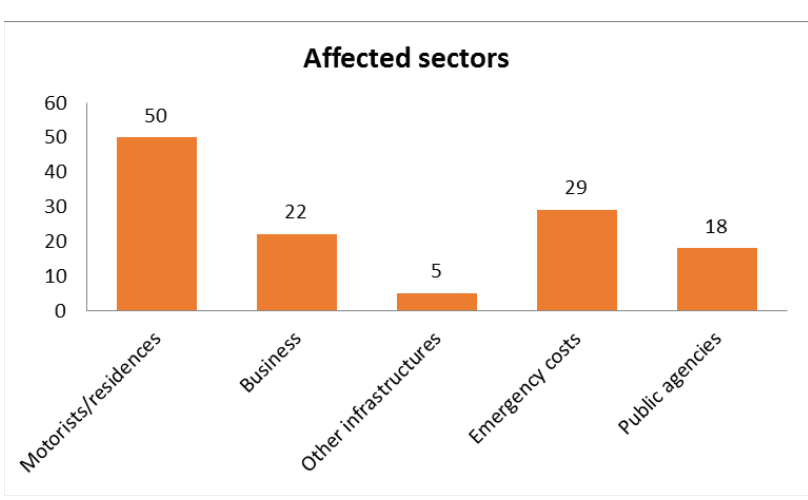

Figure 4

\subsubsection{Electricity}

Impacts to the electricity supply network were also widespread. However, less information was available regarding the factors and impacts as were available for the water and transport networks. However a forensic analysis was still able to be carried out.

During the flood event in the summer of 2007 there was a high risk that the Walham electricity sub-station, which serves Gloucestershire and parts of Wales and Herefordshire, could be flooded leading to electricity failure. Gloucestershire Fire and Rescue Service led the efforts to save Walham from flooding, calling in flood defence barriers and additional pumping equipment. The massive operation continued on 23rd July to prevent serious flooding at Walham sub-station up until the predicted high tide at $3 \mathrm{am}$. The flood defences withstood the high tide and the immediate threat of loss of electricity passed.

However, at the Castlemeads electricity sub-station, operated by Central Networks, the situation had deteriorated and surge water had overwhelmed the pumps. This led to a controlled switch off of power, initially leaving about 42,000 people in Gloucester without power. By the end of the day the number of homes without power was reduced to 1,800 .

The most significant vulnerabilities aside from the hazard were organisational and physical vulnerability followed by systemic vulnerabilities.

\section{Significance of vulnerabilities to electricity network}

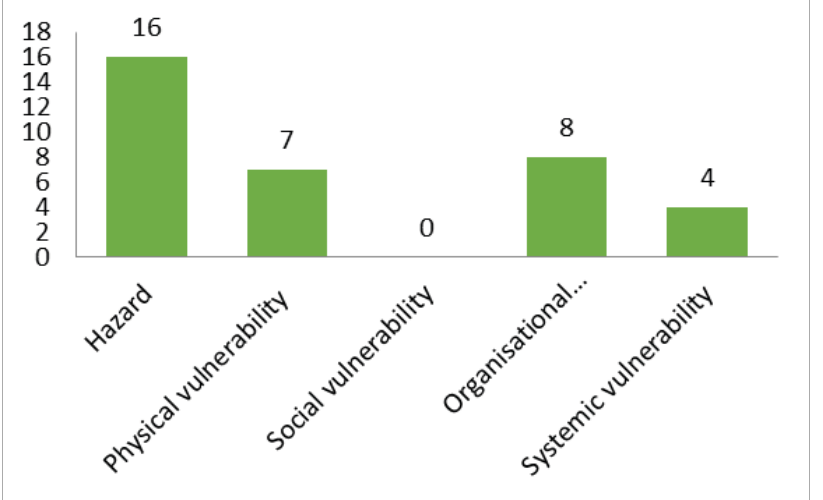

Figure 5 
The physical vulnerability of assets on the network to flooding is a major area of concern for the electricity supply companies who spend a large amount of time and money maintaining these during normal operational periods. In times of crisis this maintenance is much more resource intensive and some assets were either damaged or, shut down in order to avoid damage. The nature of electrical equipment makes it very susceptible to damage from flooding

Organisational decisions made during the emergency lead to large impacts. The decision to take the Castlemeads power station off line may have saved potential long-term damage but it affected several thousand customers and resulted in large costs to the company and disruption to operations.

Somewhat surprisingly, this analysis reveals that systemic vulnerabilities are not as significant as others. This may be down to a lack of evidence or information but it is clear that it is significant. Perhaps systemic resilience resulted in comparatively small impacts compared to the closure of the water treatment plant for example.

In terms of the most significant individual factors, the list below illustrates the contributing weight of each. It is worth noting that the weighted factor considers both contributing and reducing factors.

\begin{tabular}{|l|l|}
\hline $\begin{array}{l}\text { take over } 40,000 \text { customers off supply to } \\
\text { minimise damage to the substation }\end{array}$ & 3 \\
\hline Prolonged heavy rainfall & 3 \\
\hline Unprecedented levels of rainfall & 3 \\
\hline $\begin{array}{l}\text { water levels still remain very high around } \\
\text { the outside of the flood barrier }\end{array}$ & 2 \\
\hline EA said river levels had peaked & 2 \\
\hline Saturated soil unable to hold more & 2 \\
\hline Warmer than usual Atlantic Jet Stream & 2 \\
\hline 1 of 4 transformers de-energised & 1 \\
\hline Maintenance on drainage & 1 \\
\hline Maintenance on rivers & 1 \\
\hline Paved urban areas & 1 \\
\hline Resevoirs were full by May/June & 1 \\
\hline
\end{tabular}

Table 9 List of contributing factors affecting electricity network

As shown in Figure 6 the sectors most affected by direct damage to the electricity supply network were both the residents and businesses equally with other infrastructures, emergency costs and public agencies.

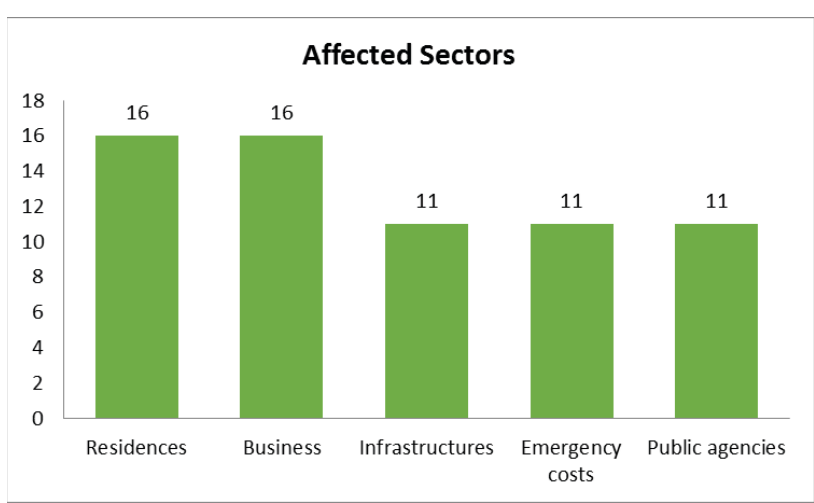

Figure 6

\subsection{Business}

Having carried out forensic investigations for each of the previously outlined infrastructure sectors, the factors that affected businesses indirectly were translated to a forensic investigation of the business sector. These factors were categorised as indirect factors while direct factors were added which were not related to infrastructure. From this point a similar process was followed as for the infrastructure sectors. The aim of the forensic investigation for businesses was to compare and contrast the effect of direct and indirect vulnerabilities.

\subsubsection{Indirect damages}

Having accumulated and analysed the impact of indirect damages to businesses caused by direct damage to infrastructure it can be seen that organisational vulnerabilities contributed more to damage than any other.

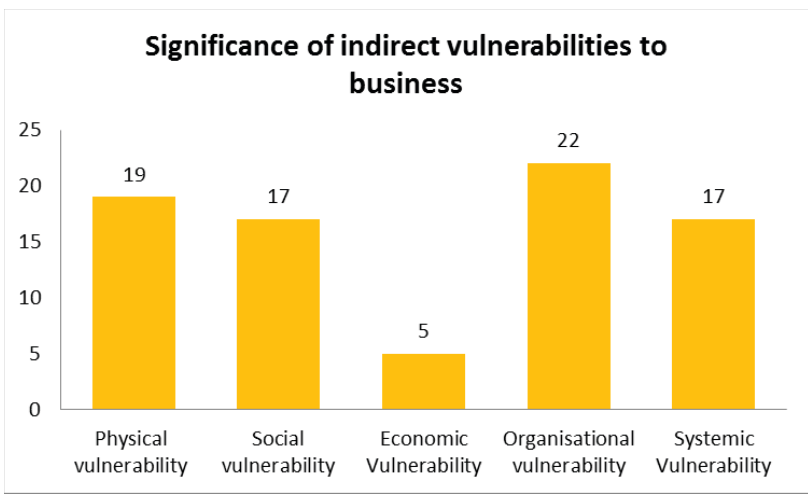

Figure 7

Organisational vulnerabilities of infrastructure refer to the decisions taken by management in the infrastructure companies that lead to increased impact on businesses. These decisions include the decision to shut the water treatment plant and the electricity supply plant for example. In relation to roads and transport they relate to the lack of communication to motorists about what to do in emergency situations.

Physical vulnerabilities were the second most significant for businesses. This includes the location of the water treatment plants and the power supply plants and roads which were all in physically vulnerable 
locations. Also the nature of the emergency was particularly hazardous for both electricity and water treatment as water can be disastrous for both.

Following physical vulnerability is systemic vulnerability which in infrastructure relates to reliance on one single element of a system which exposes end users to the risk of losing service in the case of that one element being damaged or isolated. In this case each of the infrastructure networks experienced this.

Social vulnerabilities include such factors as the misuse of water tanks that were provided by the water company once the water treatment plant had been shut down. This resulted in loss of water and damage to equipment. Additionally, the increased use of water once the closure was announced as imminent affected emergency supplies. It also refers to the ability of businesses to respond to the indirect damages as many had no previous experience of flooding of this scale and emergency services were overwhelmed. The fact that many customers were lost due to being occupied with managing their own situations affected business as did the fact that many thought that particular towns were flooded and avoided shopping there for some time after they were cleared.

Economic vulnerabilities refer to the impact that reduced custom had on business as people were occupied with dealing with the emergency.

\subsubsection{Direct damages}

Direct damages are those that directly affected businesses such as the flooding of premises, loss of stock, closure of business due to flooding, and relocation costs.

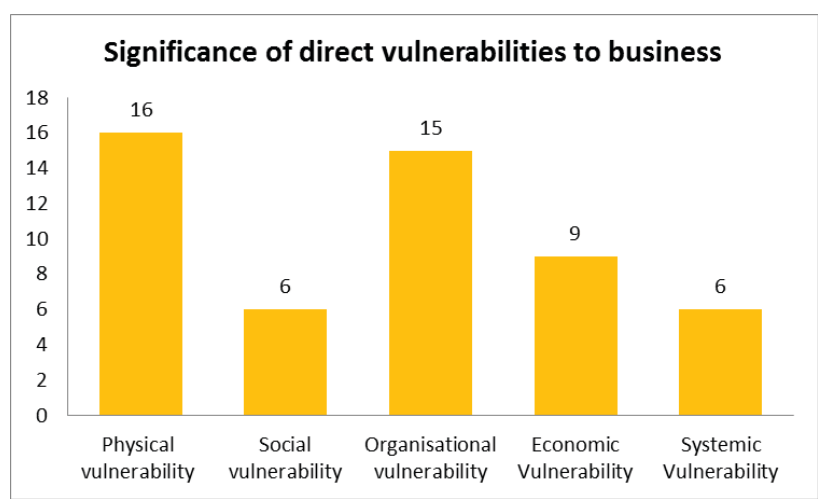

Figure 8

When it comes to direct vulnerabilities physical vulnerability is again the most significant. This relates mostly to flooding of properties and development of floodplains which led to properties being located in high flood risk areas.

Organisational vulnerabilities are the second most significant vulnerability and include the lack of knowledge with regard to recovery methods. Additionally, many businesses were not prepared for flooding and did not have business continuity plans or emergency action plans in place which led to increased damage and longer recovery times.

In contrast to indirect damages, economic vulnerabilities are more significant. This relates to the cost of repairs and recovery and to difficulties in accessing insurance and public funding.

Again in contrast to direct damage, systemic vulnerability is less significant. This is due to the nature of business in comparison with the nature of infrastructure networks which depend on many individual elements of the system to operate functionally I order to maintain constant supply of services.

\subsection{Conclusions of forensic analysis}

Several conclusions can be drawn from this in-depth analysis. Firstly, the clearest difference between indirect and direct vulnerabilities is the increased significance of economic factors. Businesses are reliant on cash flow and continuity of business in order to minimise damages. Not only does damage to stock and premises have an economic impact, so too does the loss of custom. However, the difficulty in accessing insurance and public funding and the problems related to identifying direct and indirect costs due to flooding mean that the economic vulnerabilities can leave businesses struggling for a long time after a flood.

Secondly, systemic vulnerabilities, while extremely significant for infrastructure and indirect impacts, are less so for businesses themselves. This means that improvements in the systemic resilience of networks would benefit businesses more than increasing the systemic resilience of businesses.

\section{Findings}

Having carried out a forensic investigation in order to identify the most significant vulnerabilities for businesses and assessing the relative weight of direct and indirect damages in the Severn floods of 2007, we can assess the suitability of the data for achieving our desired goal and suggest requirements for damage data to be used.

\subsection{Assessment of forensic investigation}

The forensic investigation methodology developed is very useful in identifying the root causes of damage, direct and indirect. Comparisons can be made between different sectors and how they are impacted in different ways. Also, this methodology allows us to assign contributing weights to the different sectors of the infrastructure network.

The methodology gives a comprehensive overview of the reality of the situation by drawing together factors from a wide range of perspectives thus illuminating areas that are often overlooked when it comes to damage impact analysis. The multi-disciplinary approach covers areas that relate to social, physical, organisational, economic and systemic aspects of vulnerabilities. This is very beneficial in identifying the best area for investment of funds and mitigation measures.

However, it is clear from the case study approach that any forensic analysis is only as good as the data that is used. In this case it was difficult to access primary data that would allow for more in-depth analysis, in particular 
with regard to the actual impact on businesses. While some figures can be found that refer to national estimates and some local statistics, without comprehensive knowledge of a further dataset, actual impacts must be assumed. This reduces the validity of the findings.

Secondly, the weights assigned to factors are assigned based on informed judgement and are subjective. An attempt is made to address this by using controlled parameters but often it is left open to the judgement of the investigator.

\subsection{Data requirements for forensic investigation}

As already mentioned, a forensic investigation is only as good as the data that is available. For forensic analysis to be possible and ultimately, useful, there is a need for a wide range of data to be made available regarding the event under scrutiny. For analysing natural disasters the following types of data can be regarded as the basic minimum level of detail:

- Spatial scale

- Time

- Geo-referencing

- Description of the physical damage

- Description of indirect damage

- Monetary damage (physical)

- Costs of emergency

- Costs of intervention

- Source

- Level of trust

- Additional relevant information

This is in order to obtain a general picture of the disaster impacts and to identify important features of data (scale, quality, whether or not the historical values are required, etc.).

In order to analyze this data to identify the main causes and drivers, data on the hazard factors (i.e. of the physical event), and the vulnerability factors (physical vulnerability, socio-economic data, master plans, emergency plans, laws/regulations) are required. Two steps are necessary:

1) Identify links among cause/drivers and damage to each affected sector - to identify most critical factors

2) Prioritizing factors (sector by sector) - to rate the factors in order of importance.

As a summary, Figure 9 illustrates the comprehensive range of data that are specifically related to businesses and flooding and are relevant for forensic analysis.

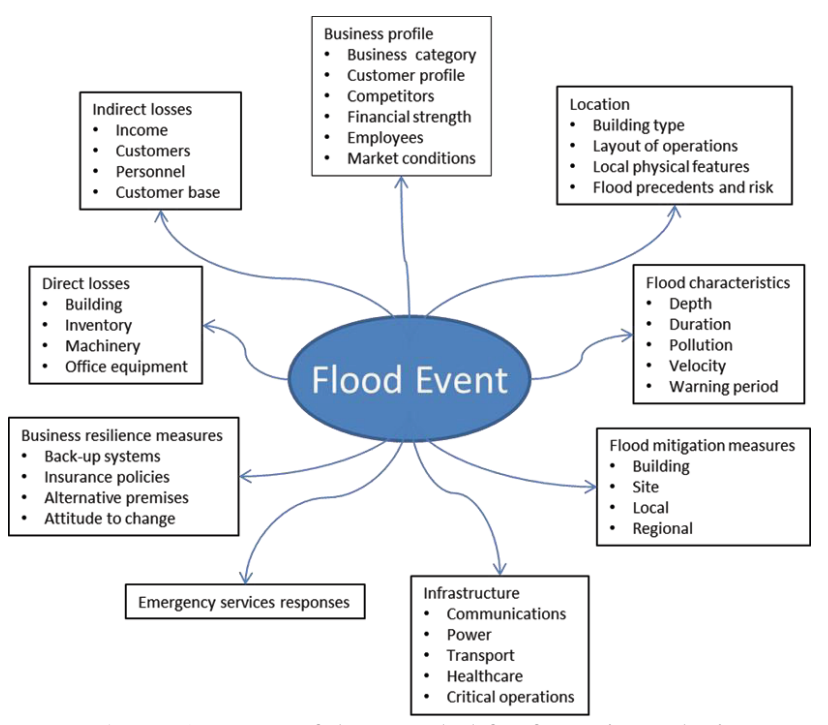

Figure 9 Range of data needed for forensic analysis in relation to businesses

Despite this comprehensive demand for data, wider investigation into the political, economic and social conditions may be needed in order to set the context within which the scenario evolved.

\begin{tabular}{|c|c|c|c|c|c|}
\hline A & B & C & D & E & F \\
\hline \multirow{2}{*}{ Sector } & \multirow{2}{*}{ Data } & \multicolumn{3}{|c|}{ STATUS } & \multirow{2}{*}{ source } \\
\hline & & acquired & $n$ aqcuisition & ot availab & \\
\hline \multirow{4}{*}{ Base maps } & DTM & $\mathrm{x}$ & & & \multirow{4}{*}{$\begin{array}{l}\text { Environment Agency } \\
\text { Environment Agency/Gloucestershire County Council/Di } \\
\text { Gloucestershire County Council/District Council/Enviror } \\
\text { Gloucestershire County Council/District Council }\end{array}$} \\
\hline & administrative boundaries & $\mathrm{x}$ & & & \\
\hline & land use & $\mathrm{x}$ & & & \\
\hline & census zones (if relevant) & & $\mathrm{x}$ & & \\
\hline \multirow{7}{*}{ Physical event } & hazard zones (from ex-ante hazard assessment) & $\mathrm{x}$ & & & \multirow{7}{*}{$\begin{array}{l}\text { Environment Agency } \\
\text { Environment Agency, Internal Drainage Board } \\
\text { Environment Agency, Internal Drainage Board } \\
\text { Environment Agency, Internal Drainage Board } \\
\text { Environment Agency, Internal Drainage Board } \\
\text { Environment Agency, Internal Drainage Board } \\
\text { Environment Agency }\end{array}$} \\
\hline & river track- for floods & $\mathrm{x}$ & & & \\
\hline & monitoring data (precipitation/water level, etc.) - for floods & $\mathrm{x}$ & & & \\
\hline & forecasting data (water level) - for floods & $\mathrm{x}$ & & & \\
\hline & affected areas & $\mathrm{x}$ & & & \\
\hline & \multicolumn{2}{|c|}{ hazard intensity (water depth, velocity, duration, sediments, contaminants, } & $\mathrm{x}$ & & \\
\hline & induced landslides & & $\mathrm{x}$ & & \\
\hline \multirow{6}{*}{$\begin{array}{l}\text { protective } \\
\text { measures (e.g. } \\
\text { dikes, walls, } \\
\text { weir) - for } \\
\text { floods }\end{array}$} & location/vulnerability (physical, functional and systemic vulnerabi & $\mathrm{x}$ & & & Environmental Agency/Local Council \\
\hline & direct damage & $\mathrm{x}$ & & & Environmental Agency/Local Council/Individual private \\
\hline & \begin{tabular}{|l|l} 
direct damage- economic value \\
\end{tabular} & $\mathrm{x}$ & & & Environmental Agency/Local Council \\
\hline & indirect damage (e.g. disruption, systemic) & & $x$ & & Environmental Agency/Local Council \\
\hline & indirect damage (e.g. disruption, systemic) - economic value & & $\mathrm{x}$ & & Environmental Agency/Local Council \\
\hline & mitigation actions (before and during the event) & & $\mathrm{x}$ & & Environmental Agency/Local Council \\
\hline \multirow{7}{*}{ People } & exposed people (e.g. census data) & & $\mathrm{x}$ & & Gloucestershire County Council/District Council \\
\hline & number of death & $\mathrm{x}$ & & & NHS/Gloucestershire Hospital Trust/Gloucestershire Fil \\
\hline & number of injured & $\mathrm{x}$ & & & NHS/Gloucestershire Hospital Trust/Gloucestershire Fil \\
\hline & number of affected people & $\mathrm{x}$ & & & NHS/Gloucestershire Hospital Trust/Gloucestershire Fil \\
\hline & number of evacuee & $\mathrm{x}$ & & & Gloucestershire Fire \& Rescue Service/National Militan \\
\hline & intangible damage & $\mathrm{x}$ & & & \\
\hline & mitigation actions (before and during the event) & & $\mathrm{x}$ & & \\
\hline \multirow{6}{*}{$\begin{array}{l}\text { Lifelines } \\
\text { (roads, } \\
\text { railways, } \\
\text { electric lines, } \\
\text { water supply, } \\
\text { sewage, }\end{array}$} & \multicolumn{2}{|c|}{ lifelines location/vulnerability (e.g. length, classification, functional and syst) } & $x$ & & Water/Sewerage/Electrical Companies \\
\hline & direct damage (lines and installation) & & $\mathrm{x}$ & & Water/Sewerage/Electrical Companies \\
\hline & direct damage (lines and installation) - economic value & & $\mathrm{x}$ & & Water/Sewerage/Electrical Companies \\
\hline & indirect damage (e.g. disruption, systemic) & & $\mathrm{x}$ & & Water/Sewerage/Electrical Companies \\
\hline & indirect damage (e.g. disruption, systemic) - economic value & & $\mathrm{x}$ & & Water/Sewerage/Electrical Companies \\
\hline & mitigation actions (before and during the event) & & $\mathrm{x}$ & & Water/Sewerage/Electrical Companies \\
\hline
\end{tabular}

Figure 10 Categories of data and agency responsible 


\subsubsection{Sources of data}

One of the problems associated with forensic investigations is where to source the required data in order to make a useful analysis. Multiple agencies have to be consulted, including local authorities, emergency services, insurance companies, the affected businesses, research organisations, members of the general public who observed the event, etc. Figure 10 provides a short summary of where some of the flood event data is stored in the case of the flood in Gloucestershire, UK in 2007.

\subsubsection{Categories of data}

Data can be categorised under the affected sector to which it concerns principally. By establishing early on which sectors are most relevant to achieving the most accurate analysis of the event, a more focused search for relevant data can be carried out. In terms of examining the effects of hazard events on businesses and establishing indirect damage it is essential to include as many sectors as possible since in effect, they will all have an indirect impact. The particular characteristics of the affected business(es) must be investigated in order to establish the pattern of their vulnerabilities and hence the most influential aspects of the hazard. In the case of the study on the Gloucestershire floods in 2007 the categories or sectors involved were: base maps, physical event, protective measures (e.g. dikes, walls, weir) - for floods, people, lifelines (roads, railways, electric lines, water supply, sewage, telecom), public items (public buildings/public spaces), strategic buildings (hospital, schools, headquarters, etc.), economic activities (commercial, industrial, agricultural), residential buildings, environment, cultural heritage and emergency management.

\subsubsection{Scales of data}

When considering what data is required for the forensic examination of a flood event related to commercial properties, the issue of scale (often also referred to as granularity) is a basic consideration. Commercial enterprises are affected by factors at a variety of scales, e.g. the direct damage to buildings and contents at the smallest scale, to disruption to infrastructure and community mechanisms at the middle scale, and local and national policy regarding flood prevention and mitigation at a national scale, and climate behaviour and geo-characteristics, such as seismic activities at global scale. The most influential factors for a particular event must be decided upon at the outset in order to limit the extent of necessary data gathering.

\section{Conclusions}

Forensic disaster investigations offer a valuable tool that offers unique insight into the root causes of disaster damage. This methodology brings together expert knowledge from a wide range of disciplines and casts a comprehensive view over political, social, economic, structural, physical and systemic vulnerabilities that is innovative and extremely useful in improving the targeting of mitigating measures that can build overall resilience.

This approach is very beneficial in an area where perspectives are often limited and isolated within particular fields of expertise and where investment can be fragmented and inefficient. The aim of such a forensic approach is to improve the cost-benefit of limited resources in tackling the underlying issues that often result in widespread damages during hazard events.

However, this approach is limited by the quantity and quality of data available and suitable data can only be relied upon if it is being collected at the right time and with the correct parameters. Quality control of data starts at collection and continues through storage, analysis and sharing. Effective collaboration across all agencies and bodies involved in data collection is a key factor in assuring reliable and useable data for forensic analysis.

Timeliness of collection can significantly affect the quality and usability of data. With many organisations reporting on the difficulties of getting staff to cut-off areas during flooding, much data is not collected at the most appropriate time, when the flood waters are at their highest. Additionally, continuous monitoring after the event to establish recovery and drying out times etc. would greatly improve the ability to estimate actual damage and impact.

The importance of a common platform for data sharing as well as of shared procedures for data collection (that envisages also the integration of present missing information) has then been identified as a key objective for the IDEA project.

Ultimately, judgements must be made regarding the reliability of any data used and this is in the hands of investigating team and ultimate responsibility lies with them.

\section{Acknowledgement}

The research described in the paper has been developed within the project "IDEA" (Improving Damage assessments to Enhance cost-benefit Analyses, EU prevention and preparedness project in civil protection and marine pollution) funded by DG-ECHO, G.A.N. ECHO/SUB/2014/694469). Authors acknowledge with gratitude all the people involved in the project.

\section{References}

1. Integrated Research on Disaster Risk. (2011). Forensic Investigations of Disasters: The FORIN Project (IRDR FORIN Publication No. 1). Beijing: Integrated Research on Disaster Risk.

2. Burton, I. (2010). Forensic disaster investigations in depth: a new case study model. Environment, 52, 36-41. 
3. Smock, R. (2002) Reducing subjectivity in qualitative risk assessments, GSEC Practical Requirements (v.1.3) (December 2001)

4. Heilemann, K., Balmand, E., Lhomme, S., De Brujin, K., Linmei, N. \& Serre, D. (2013). Identification and analysis of most vulnerable infrastructure in respect to floods. Floodprobe D2, 1 .

5. Tierney, K. (1997a). Impacts of recent disasters on businesses: The 1993 Midwest floods and the 1994 Northridge Earthquake (No. NCEER-SP0001). Buffalo: Multidisciplinary Center for Earthquake Engineering and Research, State University of New York at Buffalo.

6. McBain, W., Wilkes, D. \& Retter, M. (2010). Flood resilience and resistance for critical infrastructure, CIRIA.

7. Allenby, B. \& Fink, J. (2005). Toward inherently secure and resilient societies. Science, 309, 1034-1036.

8. Allen, C. R., Gunderson, L. \& Johnson, A. (2005). The use of discontinuities and functional groups to assess relative resilience in complex systems. Ecosystems, 8, 958-966

9. Gloucestershire County Council, (2007). Scrutiny final report. Overview and Scrutiny Management Committee. 